\title{
Unlearned lessons from a forgotten crisis
}

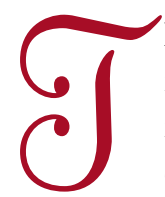

hrough this letter I like to give the readers of Europhysics News a brief flashback to October 1973, now 40 years ago. I am referring to the OPEC oil embargo, also known as the first oil crisis. Up to then, energy resources seemed unlimited and so cheap that the annual growth in Gross Domestic Product (GDP) and energy demand were nearly identical: about $5 \%$ a year, i.e., doubling every 15 years. That embargo had an immediate and negative impact on the world economy. Its message underlined a few years later by the Iran revolution - was this: energy will no longer be supplied at a non-negligible price. In fact, that price increased by an order of magnitude during the 1973-1983 decade.

As a result, a new paradigm in energy policy was born: "Energy Conservation". Commonly known as one of the most fundamental laws of physics, the term now specified the OECD countries' new Energy Policy, aimed at reducing energy vulnerability. It focused mainly on the Supply-Side (save the oil reserves), while the Demand-Side (save energy) got much less attention in general. However, in two OECD countries, Sweden and Switzerland, the energy policy has been mandatorily driven by Demand-Side technology and legislation. Various measures concerning energy efficiency and energy savings were successfully implemented. As a result, the GDPs and the energy demand were no longer similar: the former grew by $20 \%$ while the latter remained unchanged over the decade.

Many concerned physicists worldwide decided to meet the challenge, either by redirecting their own activity or by creating new labs. Many became Supply-Side (nuclear or renewable) experts. However, the Demand-Side part of energy conservation got little attention, also among physicists. From my own analysis during the last three decades, most workshops and schools on energy issues ${ }^{1}$ focus on the Supply Side, while the Demand Side remains underexposed. Yet, several experts in the field of energy conservation do exist, and in particular I wish to acknowledge our colleague, Professor Arthur H. Rosenfeld from the Lawrence Berkeley National Laboratory (LBL), widely recognised as the Godfather ${ }^{2}$ of the field. In October 1973 he moved, in one night, from Particle Physics to create LBL's 'Center for Building Science' (now EETD - Environmental Energy Technologies Division). Being the first Energy Conservation lab worldwide, EETD was rapidly regarded as an important player, both within the US and by the International Energy Agency. During 1980's and 1990's, many European physicists had the privilege to establish Energy-Efficiency R-D collaborations with Rosenfeld, not to forget the Ecocampus initiatives.

Today, each new technology is expected to be more energyefficient than the previous one. For the general public - which has only limited knowledge of underlying technology - advertisements and labels are often the only source of information, which is quite annoying from a physicist's point of view. Could our community be of any help? May I then call for a first step: more related papers in Europhysics News? Moreover, some energy systems and materials claim to decrease the user's energy or environmental footprint. May I naïvely ask a second question: when in use, is their energy balance always positive? Of course, Life-Cycle Assessment methods yield a cost/benefit energy analysis of a single piece of equipment. For complex systems however (e.g., 'zero-energy buildings', 'green cars'), this is much more difficult and less accurate. In such situations, I guess that the physicist's know-how could be more systematically called upon.

In addition, our community could demonstrate to students the energy-efficient and environmentally safe policies of their workplace. Actually, following the 1990's very modest Ecocampus initiatives, a growing list of Green Campuses is now resulting from the increasing awareness and concern. The University of Copenhagen ${ }^{3}$, where the 'demand from students in a University strategy process taking place' was one of the reasons for such an involvement, is a perfect example. Finally: the Energy Conservation paradigm, being however nothing but a "cost-of-oil-barrel" fluctuating policy, was quite appropriate $30-40$ years ago. Bearing in mind all $21^{\text {st }}$ century energy challenges (climate change, sustainability, nuclear accidents, geopolitical issues), can we keep it that way? I do not think so! Mainly relying on Demand-Side policies, Energy Sustainability is unavoidably expected to be the new paradigm. And, as an example, in such framework, future generations would gratefully acknowledge any today's decision aiming to sanctuarise the shale oil and gas reserves.

For more information I suggest the following key websites: ACEEE and ECEEE (respectively American and European Council for an Energy-Efficient Economy, which are NGOs sisters); Energy Efficiency Journal; International Journal of Sustainability in Higher Education

\section{NOTES}

${ }^{1}$ For example, the Varenna EPS-SIF International School on Energy 2012 ${ }^{2}$ See EETD's Art Rosenfeld to Receive National Medal of Technology and Innovation in 2012

${ }^{3} \mathrm{http}: / /$ climate.ku.dk/green_campus/green_results_and_indicators_/UCPH_Green_Accounts_2011_short.pdf/ contact person Tomas Refslund Poulsen, Teamleader) 